\section{The Quadriceps Muscle of Knee Joint Modelling Using Neural Network Approach: Part 2}

By: Kamaruddin, SB (Kamaruddin, Saadi Bin Ahmad) ${ }^{[1]}$; Ghani, NAM (Ghani, Nor Azura Md) ${ }^{[2]}$; Ramli, NM (Ramli, Norazan Mohamed) ${ }^{[2]}$; Nasir, NBM (Nasir, Noorhamizah Binti Mohamed) $^{[3]}$; Kader, BSB (Kader, Babul Salam Bin Ksm) ${ }^{[3]}$; Huq, MS (Huq, Mohammad Saiful) ${ }^{[3]}$

\section{IEEE CONFERENCE ON OPEN SYSTEMS}

Book Group Author(s): IEEE

Book Series: IEEE Conference on Open Systems

Pages: $53-58$

Published: 2016

Document Type: Proceedings Paper

\section{Conference}

Conference: IEEE Conference on Open Systems (ICOS)

Location: Langkawi, MALAYSIA

Date: OCT 10-12,2016

Sponsor(s): IEEE

\section{Abstract}

Artificial neural network has been implemented in many filed, and one of the most famous estimators. Neural network has long been known for its ability to handle a complex nonlinear system without a mathematical model and has the ability to learn sophisticated nonlinear relationships provides. Theoretically, the most common algorithm to train the network is the backpropagation (BP) algorithm which is based on the minimization of the mean square error (MSE). Subsequently, this paper displays the change of quadriceps muscle model by using fake savvy strategy named backpropagation neural system nonlinear autoregressive (BPNN-NAR) model in perspective of utilitarian electrical affectation (FES). A movement of tests using FES was driven. The data that is gotten is used to develop the quadriceps muscle model. 934 planning data, 200 testing and 200 endorsement data set are used as a part of the change of muscle model. It was found that BPNN-NARMA is suitable and efficient to model this type of data. A neural network model is the best approach for modelling non-linear models such as active properties of the quadriceps muscle with one input, namely output namely muscle force.

\section{Keywords}

Author Keywords: artificial neural network; backpropagation; nonlinear autoregressive; quadriceps muscle KeyWords Plus: CONTRACTION

Author Information

Reprint Address: Kamaruddin, SB (reprint author)

+ Int Islamic Univ Malaysia, Kulliyyah Sci, Computat \& Theoret Sci Dept, Jalan Istana, Kuantan 25200, Pahang Darul Ma, Malaysia.

Addresses:

+ [ 1 ] Int Islamic Univ Malaysia, Kulliyyah Sci, Computat \& Theoret Sci Dept, Jalan Istana, Kuantan 25200, Pahang Darul Ma, Malaysia

+ [2] Univ Teknol MARA, Fac Comp \& Math Sci, Ctr Stat \& Decis Sci Studies, Shah Alam 40450, Selangor Darul, Malaysia

+ [3] Univ Tun Hussein Onn Malaysia, Fac Elect \& Elect Engn, Adv Mechatron Res Grp AdMiRe, Johor Baharu 86400, Malaysia

Funding

Funding Agency Grant Number

Office for Research Management and Innovation Centre, (ORICC) of Universiti Tun Hussein Onn Malaysia (UTHM) Universiti Teknologi MARA and Malaysian Ministry of Higher Education (MOHE)

View funding text

Publisher

IEEE, 345 E 47TH ST, NEW YORK, NY 10017 USA

Categories / Classification

Research Areas: Computer Science

Web of Science Categories: Computer Science, Artificial Intelligence; Computer Science, Information Systems

See more data fields 